\title{
Nível de conhecimento sobre suporte básico de vida entre formandos da área de saúde
}

\author{
Level of knowledge about basic life support of undergraduate students from the health area
}

\author{
Carlos Augusto Pelek' (10 | carlosaugustopelek@gmail.com \\ Manoelito Ferreira Silva-Junior' ${ }^{1}$ (1) manoelito_fsjunior@hotmail.com \\ Erildo Vicente Müller ${ }^{1}$ (1) erildomuller@hotmail.com
}

\begin{abstract}
RESUMO
Introdução: O Suporte Básico de Vida (SBV) refere-se aos procedimentos que devem ser realizados em situações de parada cardiorrespiratória ou obstrução de via aérea, e, por isso, os acadêmicos e profissionais de saúde devem estar altamente capacitados para realização.

Objetivo: Determinar o nível de conhecimento sobre SBV e os fatores associados entre formandos dos cursos da área de saúde de uma universidade pública.

Método: Trata-se de um estudo transversal realizado com formandos de Educação Física, Enfermagem, Farmácia, Medicina e Odontologia da Universidade Estadual de Ponta Grossa. A coleta de dados foi realizada em 2019, no último mês de integralização curricular, por um pesquisador treinado com uso de questionário autoaplicado contendo dados sociodemográficas, formação profissional, autoconhecimento percebido e um instrumento validado de SBV. Houve associação entre o desfecho "conhecimento dos formandos" dicotomizado em alto ( $\geq 70 \%$ de acerto) ou baixo nível (<70\% de acerto) e as variáveis independentes (sociodemográficas, formação profissional e autoconhecimento percebido) e realização de regressão logística binária e multinomial $(p<0,05)$.
\end{abstract}

Resultados: Participaram do estudo 191 formandos, sendo $85,6 \%$ do universo eleito. Um total de 30 participantes (15,7\%) apresentaram alto nível de conhecimento em SBV, sendo formandos do curso de Enfermagem ( $n=12$ ) e Medicina $(n=18)$. Enquanto $35,3 \%$ dos formandos de Enfermagem e 46,2\% de Medicina apresentaram alto nível de conhecimento sobre SBV, não houve nenhum formando de Educação Física (0,0\%), Farmácia (0,0\%) e Odontologia (0,0\%). Na análise bruta, o baixo nível de conhecimento foi associado com menor idade (OR = 2,75; IC95\%: 1,22$6,21)$, não se sentir seguro para realizar o SBV $(O R=3,12$; IC95\%: 1,38-7,01) e não ter disciplina na graduação $(O R=18,35 ; \mathrm{IC} 95 \%: 2,44-138,1)$. Na análise ajustada, manteve-se não ter disciplina na graduação (OR = 13,41; IC95\%: 1,74-103,12).

Conclusão: A maioria dos formandos apresentou baixo nível de conhecimento sobre SBV, e apenas formandos em Medicina e Enfermagem demonstraram alto nível de conhecimento. Após ajuste, não ter realizado disciplina sobre a temática foi associado ao menor conhecimento sobre SBV.

Palavras-chave: Capacitação de Recursos Humanos em Saúde; Estudantes de Ciências da Saúde; Reanimação Cardiopulmonar.

\begin{abstract}
Introduction: Basic Life Support (BLS) refers to the procedures that must be performed in situations of cardiorespiratory arrest or airway obstruction, and therefore, undergraduate students and health professionals must be highly trained to perform.

Objective: To determine the level of knowledge about Basic Life Support (BLS) and the associated factors among undergraduate students from the health area in their last year of school in a public university.

Methods: This is a cross-sectional study with undergraduate students in Physical Education, Nursing, Pharmacy, Medicine and Dentistry at the Universidade Estadual de Ponta Grossa, Brazil. Data collection was carried out in 2019, in the last month of course completion, by a trained researcher using a self-administered questionnaire containing sociodemographic data, professional training, perceived self-knowledge and a validated BLS instrument. There was an association between the outcome "undergraduate students' knowledge" dichotomized as high ( $\geq 70 \%$ correct) or low level $(<70 \%$ correct) and the independent variables (sociodemographic data, professional training and perceived self-knowledge) and the performance of the binary and multinomial logistic regression $(p<0.05)$.
\end{abstract}

Results: 191 undergraduate students participated in the study, being $85.6 \%$ of the chosen universe. A total of 30 participants (15.7\%) had a high level of knowledge on BLS, being students from the Nursing $(n=12)$ and Medicine $(n=18)$ courses. While $35.3 \%$ of Nursing students and $46.2 \%$ of Medicine students had a high level of knowledge about BLS, there were no students from the Physical Education (0.0\%), Pharmacy (0.0\%) and Dentistry (0.0\%) courses. In the crude analysis, the low level of knowledge was associated with younger age (OR=2.75, 95\%Cl:1.22-6.21), not feeling safe to perform BLS (OR=3.12, 95\% Cl:1.38-7.01) and the fact that the discipline was not part of the undergraduate course (OR=18.35, 95\% Cl:2.44-138.1). In the adjusted analysis, the fact that the discipline was not part of the undergraduate course (OR=13.41, 95\%Cl:1.74-103.12) remained.

Conclusion: Most students had a low level of knowledge about BLS, and only students from the Medicine and Nursing courses demonstrated a high level of knowledge. After adjustment, the fact that the discipline was not part of the undergraduate course was associated with a lower level of knowledge about BLS.

Keywords: Health Human Resource Training; Students, Health Occupations; Cardiopulmonary Resuscitation.

1 Universidade Estadual de Ponta Grossa, Ponta Grossa, Paraná, Brasil.

Editora-chefe: Rosiane Viana Zuza Diniz ～～Editor associado: Pedro Tadao Hamamoto Filho

Recebido em 09/11/20; Aceito em 12/03/21. Avaliado pelo processo de double blind review. 


\section{INTRODUÇÃO}

As doenças cardiovasculares representam a principal causa de morte no mundo: mais pessoas morrem anualmente por essas enfermidades do que por qualquer outra causa. Estima-se que 17,7 milhões de pessoas tenham morrido por doenças cardiovasculares em 2015, representando 31\% de todas as mortes em nível global'. Entre as principais causas de paradas cardiorrespiratórias (PCR), estão infarto agudo do miocárdio, doença coronariana e arritmias cardíacas. No Brasil, no período de 2004 a 2014, 8,8\% dos óbitos se deveram a infarto do miocárdio, angina e outras doenças isquêmicas do coração².

As causas externas, como acidentes de trânsito, ferimentos por arma branca ou de fogo e obstrução de via aérea por corpos estranhos, também se configuram como fatores que podem levar à PCR. Elas representam a segunda principal causa de morte no Brasil em termos gerais, e a mais importante causa na faixa etária que compreende de 1 a 49 anos $^{3}$. No país, estima-se que, no ano de 2019, tenham ocorridos mais de 140 mil mortes decorrentes de causas externas ${ }^{4}$.

O Suporte Básico de Vida (SBV) refere-se aos procedimentos que profissionais de saúde devem realizar nos pacientes em situações de PCR ou obstrução de via aérea. A ressuscitação cardiopulmonar (RCP) é o cerne do SBV e trata-se de um conjunto de manobras realizadas para manter artificialmente o fluxo arterial ao cérebro e a outros órgãos vitais, até que ocorra o retorno da circulação espontânea ${ }^{5}$.

O sucesso da RCP depende do conhecimento teórico e também de habilidades psicomotoras por parte dos profissionais que a executam, como usar o desfibrilador externo automático (DEA) ou adotar ações para desobstrução de via aérea, entre outras medidas possíveis ${ }^{6}$. O fator tempo é uma variável determinante, pois qualquer demora no atendimento pode gerar sequelas e ter impacta na sobrevida do paciente ${ }^{7}$. Sendo assim, o treinamento dos profissionais de saúde no atendimento imediato e padronizado dessa situação clínica pode ter implicações prognósticas favoráveis ${ }^{8}$.

Os cursos de graduação da área de saúde são ambientes propícios para a formação de recursos humanos preparados para lidar com o SBV. No entanto, estudos têm mostrado baixo conhecimento sobre SBV em análises por estudantes de cursos específicos, como Medicina ${ }^{9}$ ou Enfermagem ${ }^{10}$, ou entre graduandos de cursos da área da saúde ${ }^{11,12}$. O baixo nível de conhecimento tem sido associado principalmente à ausência de treinamento prévio em SBV entre estudantes ${ }^{9,12}$ e entre profissionais com pouca experiência clínica ${ }^{13,14}$. A maioria dos estudos tem como população-alvo acadêmicos de diversos períodos $^{9,12,15}$, internos ${ }^{11}$ ou profissionais ${ }^{13,14,16,17}$, e pouca ênfase tem sido dada aos formandos de diferentes cursos da área da saúde. Nesse contexto, o presente estudo teve como objetivo determinar o nível de conhecimento sobre SBV e os fatores associados entre formandos dos cursos da área de saúde de uma universidade e pública.

\section{MATERIAL E MÉTODO}

\section{Delineamento e aspectos éticos}

Trata-se de um estudo transversal com abordagem quantitativa entre formandos dos cursos de saúde (Educação Física, Enfermagem, Farmácia, Medicina e Odontologia) da Universidade Estadual de Ponta Grossa (UEPG) do Paraná. O estudo foi previamente aprovado pelo Comitê de Ética em Pesquisa da UEPG, como consta no Certificado de Apresentação para Apreciação Ética (CAAE) nº3813818.0.0000.0105.

\section{Universo do estudo}

O estudo foi realizado com formandos dos cursos da área de saúde no ano de 2019. A universidade apresenta regime de entrada anual em todos os cursos avaliados, sendo o curso de Medicina com finalização em agosto e os demais cursos em dezembro de 2019.

O universo do estudo foi disponibilizado pela PróReitoria de Graduação e assim distribuído: bacharelado em Educação Física $(n=44)$, Enfermagem $(n=35)$, Farmácia ( $n=$ 41 ), Medicina ( $n=46$ ) e Odontologia ( $n=57)$, totalizando 223 formandos elegíveis.

Os critérios de inclusão do estudo foram: estar apto a finalizar o curso da área da saúde em 2019 e concordar em assinar o Termo de Consentimento Livre e Esclarecido (TCLE). Os critérios de exclusão foram: ter alguma disciplina em dependência que impossibilite a conclusão do curso no ano de 2019, alunos que trancaram ou desistiram do curso ou não aceitaram participar do estudo.

O curso de bacharelado em Educação Física da UEPG foi iniciado em 2010, e continua vigente a primeira versão do seu Projeto Político-Pedagógico do Curso (PPC). O curso apresenta quatro anos de integralização curricular integral, com um mínimo de 3.419 horas. O curso de bacharelado em Enfermagem da UEPG foi iniciado em 2007. A quarta versão do PPC está vigente desde 2014, com cinco anos de integralização curricular, e apresenta um mínimo de 4.800 horas. O curso de bacharelado em Farmácia da UEPG foi iniciado em 1956, e o seu PPC está na sua quinta versão e em vigência desde o ano de 2005. O curso apresenta cinco anos de integralização curricular integral, com um mínimo de 5.028 horas. O curso de bacharelado em Medicina da UEPG foi iniciado em 2009. E o PPC está na sua segunda, vigente desde 2011. O curso apresenta seis anos de integralização, perfazendo um total mínimo de 8.258 horas. $O$ curso de bacharelado em Odontologia da UEPG foi iniciado em 1956, e a turma avaliada estava na décima versão do PPC, 
implementada em 2005. O PPC apresenta um total mínimo 5.164 horas.

A oferta de disciplina específica que aborda o tema SBV está descrita na ementa de disciplinas dos cursos de Educação Física, Enfermagem e Medicina. No curso de Educação Física, há uma disciplina obrigatória denominada Noções de Higiene e Socorros de Urgência em Educação Física e Esportes, destinada à formação específica profissional, com carga horária semestral de 68 horas e cunho teórico, e oferta semestral no primeiro semestre do segundo ano letivo. Na Enfermagem, há a disciplina obrigatória de Enfermagem em Emergência destinada à formação específica profissional do curso, com carga horária de 68 horas e cunho teórico-prático, e oferta semestral no primeiro semestre do quarto ano letivo. No curso de Medicina, há as disciplinas Internato em Urgência e Emergência Cirúrgica e Internato em Urgência e Emergência Clínica, no quinto ano curricular, de cunho obrigatório, carga horária de 420 horas cada e abordagem com método teórico-prático.

\section{Coleta de dados}

A coleta de dados foi feita na própria instituição, por meio de questionário autoaplicado no final da integralização curricular, realizada em julho de 2019 para o curso de Medicina e novembro e dezembro de 2019 para os cursos de Educação Física, Enfermagem, Farmácia e Odontologia. A ferramenta estava organizada em duas partes: a primeira versou sobre dados sociodemográficos, formação profissional e autoconhecimento percebido ${ }^{18}$, e a segunda avaliou o nível de conhecimento por meio de instrumento validado em pesquisa anterior $^{12}$, contendo 20 questões de múltipla escolha, cada uma com quatro opções de resposta.

\section{Variáveis}

O desfecho do estudo foi o nível de conhecimento dos formandos, dicotomizado conforme o número de acertos de 14 (70\%) das 20 questões respondidas no questionário: alto (superior ou igual a $70 \%$ de acerto) ou baixo ( $<70 \%$ de acertos) nível de conhecimento sobre SBV. Essa linha de corte foi adotada considerando a média para aprovação nas disciplinas pela Universidade. Embora o cálculo tenha se baseado nos acertos, optou-se por não excluír da análise as questões não respondidas, e essas foram classificadas como "não acerto".

Dividiram-se as variáveis independentes da seguinte forma:

- Variáveis sociodemográficas: sexo (homem e mulher) e idade (até 24 anos e 25 anos ou mais).

- Formação profissional: curso de graduação (Educação Física, Enfermagem, Farmácia, Medicina e Odontologia) e realização de treinamento para SBV (não e sim).

- Tempo em horas de duração do curso: mais de 40 horas (não e sim) ou mais de 100 horas (não e sim), oferta de disciplina específica sobre SBV/emergências na graduação (não e sim), realização da disciplina (não e sim), modalidade da disciplina ofertada (optativa ou obrigatória), método de abordagem da disciplina (teórico e teórico-prático/prático), acreditar que a disciplina ofertada foi suficiente (não e sim).

- Autoconhecimento percebido: sente-se seguro (não/ algumas situações e sim) e acredita na necessidade de realização de cursos (não e sim).

\section{Análise dos dados}

Os dados obtidos foram armazenados em planilha Excel do Microsoft Office e posteriormente analisados por meio do programa Statistical Package for the Social Science (SPSS) versão 20.0 (IBM Corp., NY, EUA). Realizou-se a estatística descritiva por meio defrequênciasabsolutas(n)erelativas(\%).Paraaassociação entre o desfecho do estudo (alto e baixo conhecimentos) e as variáveis independentes (sociodemográficas, formação profissional e autoconhecimento percebido), utilizou-se o teste exato de Fisher ou qui-quadrado $(p<0,05)$. Houve realização de regressão por modelo logístico binário (bruto) e multinomial (ajuste) ( $p<0,05$ ), em que utilizou "alto conhecimento" como categoria de referência.

\section{RESULTADOS}

O estudo foi realizado com 191 discentes, totalizando $85,6 \%$ do universo eleito que atendia ao critério de elegibilidade: 37 acadêmicos de Educação Física (84,1\%), 34 de Enfermagem (97,1\%), 33 de Farmácia (80,5\%), 39 de Medicina (84,8\%) e 48 de Odontologia (84,2\%) (Tabela 1).

O Gráfico 1 mostra que a maior proporção de acertos foi de $40 \%(11,5 \%)$ do questionário sobre SBV, seguida de $35 \%$ e $65 \%$, com $9,4 \%$ entre os formandos participantes.

O Gráfico 2 mostra que a maior quantidade de erros ocorreu na questão 1 (90,6\%), que discorria sobre os elos de sobrevivência do lactente e da criança, seguida da questão 4 (64,9\%), a respeito da sequência da RCP após o diagnóstico de PCR. A questão com maior número de acertos foi a 10 (74,3\%), que versava sobre a manobra a ser realizada durante a abertura das vias aéreas, seguida da questão $14(69,1 \%)$, sobre o uso do DEA.

Um total de 30 participantes $(15,7 \%)$ apresentou conhecimento superior a $70 \%$, considerado no estudo como alto conhecimento sobre SBV. O maior nível de conhecimento sobre SBV foi associado aos cursos de Medicina e Enfermagem 
( $p<0,001$ ). Enquanto 35,3\% dos formandos de Enfermagem e $46,2 \%$ dos formandos de Medicina apresentaram alto nível de conhecimento de SBV, nenhum formando de Educação Física, Farmácia e Odontologia teve conhecimento suficiente (Tabela 1).

Gráfico 1.Distribuição da proporção de acertos sobre Suporte Básico de Vida entre formandos dos cursos da saúde - Ponta Grossa, PR, Brasil, 2019.

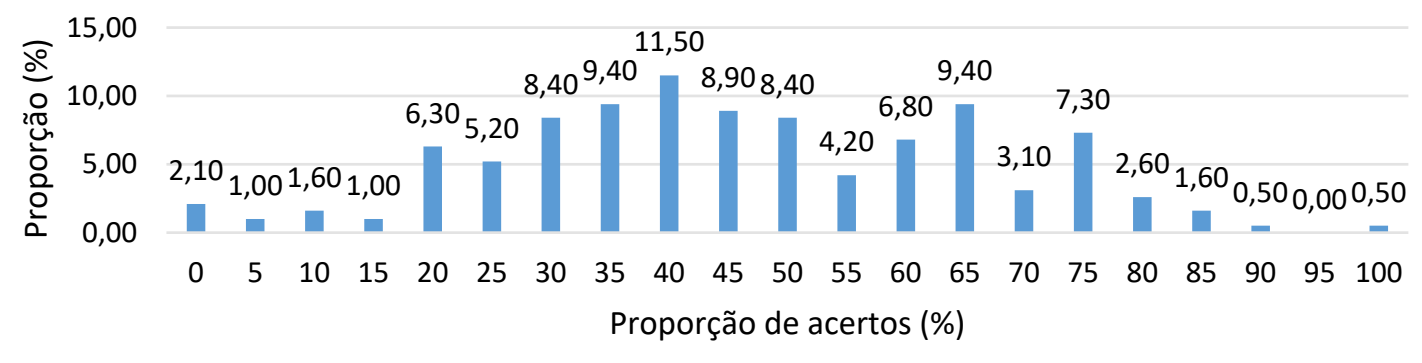

Gráfico 2.Distribuição de erros, acertos ou não respostas por questão sobre Suporte Básico de Vida entre formandos dos cursos da saúde - Ponta Grossa, PR, Brasil, 2019.



Fonte: Próprios autores.Parte inferior do formulário.

Tabela 1. Caracterização da amostra e análise bivariada entre o nível de conhecimento sobre Suporte Básico de Vida e o curso da saúde realizado por formandos - Ponta Grossa, PR, Brasil, 2019

\begin{tabular}{|c|c|c|c|c|}
\hline \multirow[b]{2}{*}{ Curso } & \multicolumn{2}{|c|}{ Nível de conhecimento } & \multirow{2}{*}{$\begin{array}{l}\text { Total } \\
\text { n (\%) }\end{array}$} & \multirow[b]{2}{*}{ p-valor } \\
\hline & $\begin{array}{l}\text { Baixo } \\
\text { n (\%) }\end{array}$ & $\begin{array}{c}\text { Alto } \\
\text { n (\%) }\end{array}$ & & \\
\hline Enfermagem & $22(13,7)$ & $12(40,0)$ & $34(17,8)$ & $<0,001$ \\
\hline Educação Física & $37(23,0)$ & $0(0,0)$ & $37(19,4)$ & \\
\hline Farmácia & $33(20,5)$ & $0(0,0)$ & $33(17,3)$ & \\
\hline Medicina & $21(13,0)$ & $18(60,0)$ & $39(20,4)$ & \\
\hline Odontologia & $48(29,8)$ & $0(0,0)$ & $48(25,1)$ & \\
\hline Total & $161(100,0)$ & $30(100,0)$ & $191(100,0)$ & \\
\hline
\end{tabular}


Na Tabela 2, observam-se a caracterização da amostra e a análise bivariada. Verificou-se que a maioria dos participantes era do sexo feminino (64,9\%) e com até 24 anos de idade (74,9\%). Dos participantes, $64,6 \%$ se mostraram seguros para realizar atendimento de primeiros socorros, $63,3 \%$ afirmaram ter treinamento prévio extracurricular e $66,8 \%$ confirmaram a oferta de disciplina relacionada ao tema. A maioria considerou a disciplina insuficiente $(60,2 \%)$ e manifestou a necessidade de realização de novos cursos dentro do tema $(90,0 \%)$.

$\mathrm{Na}$ análise bruta, houve maior chance de apresentar baixo nível de conhecimento em SBV entre os formandos com menor idade (OR = 2,75; IC95\%: 1,22-6,21), não se sentir seguro para realizar (OR =3,12; IC95\%:1,38-7,01) e não ter tido recebido oferta de disciplina na graduação (OR = 18,35; IC95\%: 2,44$138,1)$. Após ajuste, apenas não ter tido oferta de disciplina na graduação foi associado a baixo nível de conhecimento sobre SBV (OR = 13,41; IC95\%: 1,74-103,12) (Tabela 3).

\section{DISCUSSÃO}

No presente estudo, a maioria dos formandos da área da saúde apresentou baixo nível de conhecimento sobre SBV, principalmente os dos cursos de Educação Física, Farmácia e Odontologia. Na literatura, outros estudos têm demonstrado o baixo nível de conhecimento sobre SBV entre acadêmicos ${ }^{9,10,12}$, seja em estudos com maior rigor na proporção de acertos na definição de alta e/ou baixo conhecimento sobre SBV, como de $84 \%{ }^{12}$ ou $50 \%{ }^{9}$. Na literatura há uma variação grande na prevalência de acertos, de $0,1 \%{ }^{12}$ a $13 \%$ entre acadêmicos de Medicina ${ }^{9}$ e $25 \%$ para graduandos em Enfermagem ${ }^{10}$. A diferença verificada no presente estudo em relação à literatura nacional $^{12}$ e à internacional ${ }^{11}$ pode ter ocorrido por conta

Tabela 2. Caracterização da amostra e análise bivariada entre o nível de conhecimento sobre Suporte Básico de Vida e variáveis independentes entre formandos dos cursos da saúde - Ponta Grossa, PR, Brasil, 2019

\begin{tabular}{|c|c|c|c|c|c|}
\hline \multirow[b]{2}{*}{ Variáveis } & \multirow[b]{2}{*}{ Categorias } & \multicolumn{3}{|c|}{ Nível de conhecimento } & \multirow[b]{2}{*}{ p-valor } \\
\hline & & $\begin{array}{l}\text { Baixo } \\
\text { n (\%) }\end{array}$ & $\begin{array}{l}\text { Alto } \\
\text { n (\%) }\end{array}$ & $\begin{array}{l}\text { Total } \\
\text { n (\%) }\end{array}$ & \\
\hline \multirow{2}{*}{ Sexo } & Mulher & $104(64,6)$ & $20(66,7)$ & $124(64,9)$ & \multirow{2}{*}{0,827} \\
\hline & Homem & $57(35,4)$ & $10(33,3)$ & $67(35,1)$ & \\
\hline \multirow{2}{*}{ Idade } & Até 24 anos & $126(78,3)$ & $17(56,7)$ & $143(74,9)$ & \multirow[t]{2}{*}{0,012} \\
\hline & 25 anos ou mais & $35(21,7)$ & $13(43,3)$ & $48(25,1)$ & \\
\hline \multirow{2}{*}{ Sente-se seguro } & $\begin{array}{l}\text { Não/em algumas } \\
\text { situações }\end{array}$ & $110(68,8)$ & $12(41,4)$ & $122(64,6)$ & \multirow[t]{2}{*}{0,005} \\
\hline & Sim & $50(31,2)$ & $17(58,6)$ & $67(35,4)$ & \\
\hline \multirow{2}{*}{ Realizou treinamento } & Não & $58(36,7)$ & $11(36,7)$ & $69(36,7)$ & \multirow[t]{2}{*}{0,996} \\
\hline & Sim & $100(63,3)$ & $19(63,3)$ & $119(63,3)$ & \\
\hline \multirow{2}{*}{ Realizou curso com mais de 100 horas } & Não & $69(90,8)$ & $10(90,9)$ & $79(90,8)$ & \multirow[t]{2}{*}{0,999} \\
\hline & $\operatorname{Sim}$ & $7(9,2)$ & $1(9,1)$ & $8(9,2)$ & \\
\hline \multirow{2}{*}{ Realizou curso com mais de 40 horas } & Não & $36(47,4)$ & $6(54,5)$ & $42(48,3)$ & \multirow[t]{2}{*}{0,656} \\
\hline & Sim & $40(52,6)$ & $5(45,5)$ & $45(51,7)$ & \\
\hline \multirow{2}{*}{ Oferta de disciplina na graduação } & Não & $62(38,8)$ & $1(3,3)$ & $63(33,2)$ & \multirow[t]{2}{*}{$<0,001$} \\
\hline & Sim & $98(61,3)$ & $29(96,7)$ & $127(66,8)$ & \\
\hline \multirow{2}{*}{ Tipo de disciplina ofertada } & Optativa & $6(6,4)$ & $2(6,9)$ & $8(6,5)$ & \multirow[t]{2}{*}{0,922} \\
\hline & Obrigatória & $88(93,6)$ & $27(93,1)$ & $115(93,5)$ & \\
\hline \multirow{2}{*}{ Cursou a disciplina } & Não & $1(14,3)$ & $0(0,0)$ & $1(11,1)$ & \multirow[t]{2}{*}{0,571} \\
\hline & Sim & $6(85,7)$ & $2(100)$ & $8(88,9)$ & \\
\hline \multirow{2}{*}{ Acredita que a disciplina ofertada foi suficiente } & Não & $55(60,4)$ & $16(59,3)$ & $71(60,2)$ & \multirow[t]{2}{*}{0,912} \\
\hline & $\operatorname{Sim}$ & $36(39,6)$ & $11(40,7)$ & $47(39,8)$ & \\
\hline \multirow{2}{*}{ Método de abordagem da disciplina } & Teórico & $5(5,4)$ & $3(10,7)$ & $8(6,6)$ & \multirow[t]{2}{*}{0,319} \\
\hline & Teórico-prático/prático & $88(94,6)$ & $25(89,3)$ & $113(93,4)$ & \\
\hline \multirow{2}{*}{ Acredita na necessidade de cursos } & Não & $17(10,6)$ & $2(6,7)$ & $19(10,0)$ & \multirow[t]{2}{*}{0,507} \\
\hline & Sim & $143(89,4)$ & $28(93,3)$ & $171(90,0)$ & \\
\hline
\end{tabular}


Tabela 3. Análise de associação bruta e ajustada entre o baixo nível de conhecimento sobre Suporte Básico de Vida e variáveis independentes entre formandos dos cursos da saúde - Ponta Grossa, PR, Brasil, 2019.

\begin{tabular}{|c|c|c|c|c|}
\hline \multirow{2}{*}{ Variáveis } & \multicolumn{3}{|c|}{ Baixo nível de conhecimento } & \multirow{2}{*}{ p-valoı } \\
\hline & ORa (IC95\%) & p-valor & ORb (IC95\%) & \\
\hline \multicolumn{5}{|l|}{ Idade } \\
\hline 25 anos ou mais & 1,00 & & 1,00 & \\
\hline Até 24 anos & $2,75(1,22-6,21)$ & 0,015 & $1,76(0,74-4,21)$ & 0,197 \\
\hline \multicolumn{5}{|l|}{ Se sente seguro } \\
\hline Sim & 1,00 & & 1,00 & \\
\hline Não/em algumas situações & $3,12(1,38-7,01)$ & 0,006 & $2,26(0,97-5,29)$ & 0,600 \\
\hline \multicolumn{5}{|l|}{ Oferta de disciplina na graduação } \\
\hline Sim & 1,00 & & 1,00 & \\
\hline Não & $18,35(2,44-138,1)$ & 0,005 & $13,41(1,74-103,12)$ & 0,013 \\
\hline
\end{tabular}

a Odds ratio bruta; ${ }^{\text {b }}$ odds ratio ajustada.

A variável "curso de formação", apesar de ser estatisticamente diferente na análise bivariada, não foi utilizada na regressão porque não houve nenhum acerto entre alguns cursos analisados.

do instrumento utilizado, como a variação no conteúdo das questões para avaliação do conhecimento sobre SBV, ou por causa da formação profissional entre as realidades em cada um dos cursos do campo da saúde. Apesar de os dados desta pesquisa referirem-se a formandos, estudos têm verificado o baixo desempenho também entre profissionais, em que 10,2\% dos médicos e enfermeiros de um hospital público tinham alto conhecimento sobre SBV ${ }^{17}$.

Os cursos de Medicina e Enfermagem foram os únicos que apresentaram formandos com alto nível de conhecimento, sem nenhum dos cursos de Educação Física, Farmácia e Odontologia com acertos acima de 70,0\%. Um estudo com o mesmo questionário realizado em São Paulo mostrou dados semelhantes, no qual houve maior nível de conhecimento entre os alunos do curso de Medicina, seguido de Enfermagem ${ }^{12}$. Um estudo realizado na Arábia Saudita não mostrou diferença no conhecimento entre os acadêmicos dos cursos de Medicina, Odontologia, Enfermagem e Farmácia ${ }^{11}$. Os resultados obtidos no presente estudo, com prevalência de alto conhecimento nos cursos de Medicina e Enfermagem em comparação com outros estudos ${ }^{9,11,12}$, podem decorrer de análise apenas com formandos, e não com acadêmicos de diferentes anos de integralização do curso. Além disso, o maior desempenho entre formandos desses cursos pode estar atrelado à oferta da disciplina mais ao final da integralização curricular, ofertada próximo à realização do internato, realizada principalmente em ambiente hospitalar, e, consequentemente, com maior probabilidade de uso das práticas de SBV na rotina acadêmica. Essa realidade torna-se diferente do curso da Educação Física, que, apesar de apresentar mesma carga horária quando comparada à Enfermagem, tem abordagem teórica e ocorre no início da integralização curricular, e não houve nenhum acadêmico com alto conhecimento. Além disso, quando se considera um estudo apenas com elegibilidade de acadêmicos formandos, como no presente estudo, há um maior distanciamento entre o momento de abordagem conteúdo abordado na disciplina e o momento da coleta de dados. Os demais cursos, Farmácia e Odontologia, não apresentaram o conteúdo de SBV na ementa das disciplinas ofertadas, o que pode demonstrar o baixo conhecimento. Esse aspecto já foi revisto pelo curso de Odontologia: o novo PPC, em sua décima primeira versão, em vigência desde 2016, incluiu o conteúdo na disciplina de Diagnóstico e Cirurgia Bucal III, ofertada no terceiro ano curricular, com carga horária de 136 horas e cunho teórico-prático.

Os maiores índices de acertos foram encontrados nas questões a respeito da abertura de vias aéreas e do uso do DEA. Outros trabalhos também verificaram maior índice de acerto na questão referente à abertura de vias aéreas ${ }^{19}$, e um estudo com médicos recém-formados constatou o mesmo resultado no que concerne ao uso do $D_{E A}{ }^{13}$. Estudo realizado com profissionais da enfermagem apontou maior taxa de acertos na questão referente ao reconhecimento da PCR e ao manejo inicial, mas maior número de erros na questão sobre abertura de vias áreas e ventilação ${ }^{16}$. 0 maior índice de acertos nesses assuntos pode estar atrelado ao fato de eles serem temas mais gerais e abordados de maneira mais difundida.

No presente estudo, houve maior número de erros nas questões relacionadas aos elos da cadeia de sobrevivência do lactente e da criança, e sobre a sequência da RCP após o diagnóstico de PCR. Os assuntos relacionados à lactente e criança dentro do SBV foram pouco abordados na literatura ${ }^{10}$, dando preferência aos procedimentos em adultos, e, por isso, 
a dificuldade de comparabilidade dos achados no presente estudo. No entanto, outros estudos verificaram grande proporção de erro nas questões sobre sequência da $R C P^{11,19}$. A dificuldade no aprendizado desses assuntos pode ser atribuída à ausência de estudo consistente e contínuo por parte dos acadêmicos.

$\mathrm{Na}$ análise bruta, a idade foi um fator associado, em que os formandos mais jovens apresentaram menor nível de conhecimento sobre SBV. Outros estudos com acadêmicos mostraram que os estudantes em períodos mais avançados dos cursos obtiveram maior número de acertos ${ }^{12}$, como também em pesquisa com o público leigo em Portugal, em que a maior idade foi associada a maior nível de conhecimento ${ }^{20}$. Já outro estudo, também com público leigo, realizado em Minas Gerais não verificou essa associação ${ }^{21}$, o que também não foi verificado entre profissionais médicos e enfermeiros ${ }^{17}$. A diferença de resultados pode estar associada à diferença de metodologia $e$ ao público-alvo participante do estudo. Apesar de ter mais idade não implica necessariamente em possuir maior conhecimento, é possível presumir que pessoas mais velhas tenham tido mais oportunidades de passar por experiências de aprendizado ou necessidade prática da sua aplicação, ou seja, não seria a idade um preditor direto, mas a maior experiência profissional clínica, em estudos com acadêmicos ou profissionais da área, ou a maior maturidade entre indivíduos mais velhos para lidar com situações adversas, no caso de estudos com leigos.

O fato de este estudo considerar cursos com tempos de integralização diferentes - por exemplo, Educação Física em quatro anos e Medicina em seis - pode ter interferido nos resultados. Além disso, como o ingresso em uma instituição de ensino é, em geral, mais tardio por conta o vestibular concorrido, o curso de Medicina pode apresentar acadêmicos mais velhos. Deve-se considerar ainda a possibilidade de os acadêmicos em Enfermagem terem realizado previamente um curso técnico na área. Com base nesses aspectos, o resultado deve ser visto com cuidado, pois trata-se de variáveis de difícil interpretação. Quando se ajustaram os resultados, não se verificou associação de idade no modelo final.

Na análise bruta, houve a associação de dois aspectos: não sentir-se seguro para realizar o SBV e baixo conhecimento. Além disso, constatou-se que o fato de uma minoria dos formandos sentir-se segura ou capaz de realizar procedimentos emergenciais precisa ser explorado, o que demonstra uma necessidade prioritária para um manejo de capacitação desses futuros profissionais. Um estudo com enfermeiras verificou correlação positiva moderada entre a realização dos procedimentos de SBV e a experiência clínica ${ }^{14}$, e um estudo com médicos recém-formados mostrou associação entre maior tempo de prática clínica e maior segurança em realizar $\mathrm{RCP}^{13}$. No presente estudo, observou-se que os formandos em saúde com maior tempo em ambiente hospitalar, como em Medicina e Enfermagem, inclusive com relação à realização de internato, sentem-se mais preparados para lidar com questões do SBV.

A não realização de disciplina sobre SBV durante a graduação foi associada ao baixo nível de conhecimento, tanto em análise bruta como na análise ajustado, e, por isso, dentro da limitação do presente estudo, a inclusão de disciplinas curriculares parece ser a forma mais adequada para formação dos futuros profissionais da saúde sobre SBV. Enquanto os estudos mostram associação do nível de conhecimento com realização de curso prévio em SBV ${ }^{9,12,16}$, essa variável não foi associada no presente estudo, seja em treinamentos, cursos com menor ou maior carga horária. Esse aspecto pode ser resultado da baixa adesão aos cursos extracurriculares pelos participantes no presente estudo, apesar de 90,0\% terem afirmado que a realização dos cursos é importante. Diversos fatores podem explicar esse resultado: o custo envolvido, a metodologia empregada nos cursos, a não obrigatoriedade de realização ou a expectativa dos acadêmicos em relação à possibilidade de o conteúdo fazer parte das atividades curriculares. Além disso, no Brasil, infelizmente não há uma cultura de medidas preventivas de segurança com realização de simulações e/ou treinamento pontuais e/ou contínuos para desastres de diversas naturezas.

Dessa forma, os resultados do presente estudo demonstraram que a presença de uma disciplina ofertada no PPC dos cursos da área da saúde apresentou impacto maior no nível de conhecimento do que nos cursos extracurriculares prévios realizados. Isso pode estar atrelado ao fato de as disciplinas terem uma carga horária distribuída em um processo de ensino-aprendizagem contínuo, e não pontual, como cursos de capacitação. Além disso, a oferta de disciplinas curriculares com atividades avaliativas que seguem o padrão para verificação de aprendizagem pode ser mais efetiva para acadêmicos, já que essa metodologia é menos frequente cursos de capacitação.

Apesar das contribuições presentes no estudo, devem-se destacar algumas limitações, como a variabilidade metodológica nos estudos presentes na literatura e, por isso, dificuldades para comparabilidade. Encontraram-se diferentes instrumentos de coleta para mensuração do conhecimento em SBV que, apesar de validados, não eram iguais ${ }^{11,12,20}$. Dentre esses, o questionário de Tavares et al. ${ }^{12}$ foi selecionado por ter sido validado em português e aplicado para amostra contendo diferentes cursos, e possuir grande número de questões. O uso de um questionário de outro estudo brasileiro ${ }^{12}$ que obteve resultados semelhantes aos aqui apresentados pode reforçar a sensibilidade do questionário em mensurar o SBV e a sua reprodutibilidade, mesmo em amostras de locais diferentes, e assim pareceu ser um instrumento adequado para avaliar o conhecimento. No entanto, o estudo indicava uma linha de 
corte para alto nível, com $84 \%{ }^{22}$, parâmetro considerado alto, em que um número limitado de participantes conseguiu atingir essa proporção. Sendo assim, considerando a média para aprovação na instituição, optou-se por reduzir para 70\% o nível de corte e o conhecimento considerado adequado.

Outro aspecto que deve ser esclarecido é a limitação do uso de questionário para mensuração do nível de conhecimento em SBV. Sobre o conteúdo procedimental, uma avaliação apenas em nível cognitivo no campo teórico torna-se uma maneira limitada da problemática. Ou seja, se os resultados aqui explícitos em nível cognitivo demonstraram baixo nível de conhecimento, eles poderiam ser ainda piores se fossem realizados testes práticos. No entanto, o uso de questionários ainda é a principal forma de aferir o conhecimento, seja pelo baixo custo ou pela facilidade de aplicação nos diferentes locais do mundo, como Brasil ${ }^{12}$, Peru ${ }^{9}$, Reino Unido ${ }^{15}$ ou Oriente Médio ${ }^{11}$, sendo instrumentos baseados em guidelines sobre o assunto e posteriormente validados. No entanto, a existência de questionário padronizado e universal seria importante para maior comparabilidade dos resultados em diferentes amostras populacionais. Além disso, a realização de estudos longitudinais, capazes de envolver a evolução do conhecimento dos acadêmicos ao longo de sua formação, é incentivada para entender qual seria o momento ideal de formação para a inclusão da disciplina sobre o SBV. O uso de estratégias de coleta dos dados que também incluíssem a verificação de aprendizagem em nível prático poderia trazer dados mais condizentes com a realidade sobre o nível de conhecimento dos participantes.

Outra questão a ser considerada por estudos futuros é a mensuração sobre participação em atividades extracurriculares na área de urgência/emergência, como ligas, monitorias ou projetos de extensão na área. Esse dado poderia auxiliar na melhor compreensão do conhecimento apreendido e, inclusive, na maior propensão de interesse no tema conforme a especialidade futura pretendida.

Além disso, a amostra é outro fator de difícil comparabilidade. Enquanto alguns estudos incluem apenas como universo um curso da saúde ${ }^{9,10,15}$, outros consideram vários cursos, independentemente do semestre ou ano ${ }^{11,12,19}$, e outros os realizam com profissionais de saúde formados ${ }^{13,14,17}$ e até mesmo leigos ${ }^{20,21}$. O presente estudo trabalhou apenas com acadêmicos formandos, no intuito de reduzir o viés de memória e aumentar a confiabilidade de mensuração sobre o conhecimento significativo. Nesse sentido, os dados do presente estudo tornam-se preocupantes quando se considera que, antes da atuação em área específica de cada profissão no âmbito da saúde, os formandos precisam entender que são profissionais de saúde e, por essa razão, devem estar preparados para lidar com situações emergenciais dentro e fora dos serviços de saúde. Sendo assim, cada vez mais a integralidade e a interdisciplinaridade devem fazer parte da formação de recurso humanos em saúde.

Constatou-se que o conhecimento sobre SBV não foi absorvido pela maioria dos formandos, ou seja, eles não estão devidamente preparados para o mercado de trabalho. Esse resultado reforça a necessidade de inclusão de disciplina permanente sobre SBV nas instituições de ensino superior, para todos os cursos da área da saúde e, principalmente, com uma perspectiva adequada para as necessidades comuns dentro do campo de atuação de cada profissional da saúde, bem como cursos de reciclagem e manutenção do conhecimento para profissionais já formados, uma vez que, mesmo apresentando cursos de capacitação, a falta de aplicabilidade contínua dos conhecimentos apreendido pode reduzir ao longo do tempo a capacidade de utilização dos procedimentos clínicos necessários em casos específicos de SBV.

\section{CONCLUSÃO}

A maioria dos participantes deste estudo apresentou baixo nível de conhecimento sobre SBV, e apenas os discentes de Medicina e Enfermagem demonstraram alto nível de conhecimento.

O baixo nível de conhecimento sobre SBV foi associado a menor idade, não sentir-se seguro na realização de procedimentos e não ter realizado disciplina sobre a temática durante a formação profissional. No entanto, após ajuste, apenas não ter realizado disciplina sobre a temática foi associado ao baixo conhecimento sobre SBV.

\section{CONTRIBUIÇÃO DOS AUTORES}

Carlos Augusto Pelek participou do desenho do estudo e da coleta dos dados, e redigiu o artigo científico. Manoelito Ferreira Silva-Junior participou do desenho do estudo, supervisionou todas as etapas do estudo e fez a análise dos dados e a correção final do artigo científico. Erildo Vicente Müller participou do desenho do estudo e da análise dos dados, e fez a correção e revisão final do artigo.

\section{CONFLITO DE INTERESSES}

Os autores declaram não haver conflito de interesses neste estudo.

\section{FINANCIAMENTO}

Declaramos que não houve financiamento para a realização desta pesquisa. 


\section{REFERENCIAS}

1. Organização Pan-Americana da Saúde. Doenças cardiovasculares. Opas; 2017 [access in 26 may 2019]. Available from: https://www.paho.org/ bra/index.php?option=com_content\&view =article\&id=5253:doencascardiovasculares\&ltemid $=1096$.

2. Sociedade Brasileira de Cardiologia. Cardiômetro. Mortes por doenças cardiovasculares no Brasil: 2015 [acesso em 26 maio 2019]. Disponível em: http://www.cardiometro.com.br/anteriores.asp.

3. Marques SHB, Souza AC, Vaz AA, Pelegrini AHW, Linch GFC. Mortalidade por causas externas no Brasil de 2004 a 2013. Rev Baiana Saúde Pública. 2017;41(2):394-409.

4. Brasil. Banco de dados do Sistema Único de Saúde - DATASUS. Óbitos por causas externas. Brasília: Ministério da Saúde; 2019 [access in 9 jan 2021]. Available from: http://tabnet.datasus.gov.br/cgi/tabcgi.exe?sim/ cnv/ext10uf.def.

5. Tallo FS, Moraes Junior R, Guimarães HP, Lopes RD, Lopes AC. Atualização em reanimação cardiopulmonar: uma revisão para o clínico. Rev Soc Bras Clín Méd. 2012;10(3):194-200.

6. American Red Cross. Basic Life Support for healthcare providers handbook. Stamford: Staywell; 2015 [acesso em 10 set 2018]. Disponível em: https:// topguardtraining.com/wp-content/uploads/2018/01/BLS-Participant.pdf.

7. Hasselqvist-Ax I, Riva G, Herlitz J, Rosenqvist M, Hollenberg J, Nordberg P, et al. Early cardiopulmonary resuscitation in out-of-hospital cardiac arrest. N Engl J Med. 2015;372:2307-15.

8. Mauri R, Burkart R, Benvenuti C, Caputo ML, Moccetti T, Del Bufalo A, et al. Better management of out-of-hospital cardiac arrest increases survival rate and improves neurological outcome in the Swiss Canton Ticino. Europace. 2016;18:398-404.

9. Mejia CR, García-Saavedra MB, Benites-Flores IR, Ordinola-Calle DD, FailocRojas VE, Valladares-Garrido D, et al. Associated factors with knowledge of basic life support in medical students from nine Peruvian universities. Rev Mex Cardiol. 2016;27(4):148-55.

10. Silva DV, Jesus APS, Lima AA, Santos MSAS, Alves SL. Conhecimento de graduandos em enfermagem sobre suporte básico de vida. Rev Baiana Enferm. 2015;29(2):125-34.

11. Saquib SA, Al-Harthi HM, Khoshhal AA, Shaher AA, Al-Shammari AB, Khan $A$, et al. Knowledge and attitude about Basic Life Support and Emergency Medical Services amongst healthcare interns in University Hospitals: a cross-sectional study. Emerg Med Int. 2019;2019:1-8.
12. Tavares LFB, Bezerra IMP, Oliveira FR, Sousa LVA, Raimundo RD, Sousa EC, et al. Conhecimento de estudantes de graduação em ciências da saúde em testes objetivos sobre suporte básico de vida. J Human Growth Dev. 2015;25(3):297-306.

13. Chew KS, Hashairi FM, Zarina ZI, Farid AWS, Yazid MNA, Hisamuddin NARN. A survey on the knowledge, attitude and confidence level of adult cardiopulmonary resuscitation among junior doctors in Hospital Universiti Sains Malaysia and Hospital Raja Perempuan Zainab II, Kota Bharu, Kelantan, Malaysia. Med J Malaysia. 2011;66(1):56-9.

14. Uhm DC, Hwang JY, Jun MH, Kim DO. Structural equation model of clinical nurses' willingness to perform Basic Life Support (BLS) in South Korea. Journal of the Korea Academia-Industrial Cooperation Society. 2016;7(2):290-8.

15. Willmore RD, Veljanoski D, Ozdes F, Stephens B, Mooney J, Crumley SG, et al. Do medical students studying in the United Kingdom have an adequate factual knowledge of basic life support? World J Emerg Med. 2019;10(2):75-80.

16. Santos MS, Toledo LV, Alves KR, Santana MMR, Ribeiro L, Diaz FBBS Conhecimento da equipe de enfermagem do setor de hemodiálise sobre o atendimento a parada cardiorrespiratória. HU Rev. 2017;43(3):375-81.

17. Oliveira SFG, Moreira SMBP, Vieira LL, Gardenghi G. Conhecimento de parada cardiorrespiratória dos profissionais de saúde em um hospital público: estudo transversal. Rev Pesqui Fisioter. 2018;8(1):101-9.

18. Zanesco C, Galvan J, Galvão N, Bordin D, Fadel CB. Conhecimento e segurança de universitários da área de ciências biológicas e da saúde sobre primeiros socorros. Rev Pesqui. 2020;12: 154-60.

19. Hung MSY, Chow MCM, ChuTTW, Wong PP, Nam WY, Chan VLK, et al. College students' knowledge and attitudes toward bystander cardiopulmonary resuscitation: a cross-sectional survey. Cogent Med. 2017;4(1):e1334408.

20. Dixe MACR, Gomes JCR. Conhecimento da população portuguesa sobre Suporte Básico de Vida e disponibilidade para realizar formação. Rev Esc Enferm USP. 2015;49(4):640-9.

21. Chehuen Neto JA, Bru IV, Pereira DR, Santos LG, Moraes SL, Ferreira RE. Conhecimento e interesse sobre suporte básico de vida entre leigos. Int $J$ Cardiovasc Sci. 2016;29(6):443-52.

22. American Heart Association. Basic life support: instructors essentials faculty guide. 2018 [access in 8 jun 2019]. Available from: https:// ahainstructornetwork.americanheart.org/idc/groups/ahaecc-public/@ wcm/@ecc/documents/downloadable/ucm_499295.pdf. 